\title{
Optimizing GaNP Coaxial Nanowires for Efficient Light Emission by Controlling Formation of Surface and Interfacial Defects
}

Jan Eric Stehr, Alexander Dobrovolsky, S. Sukrittanon, Yanjin Kuang, C. W. Tu, Weimin

Chen and Irina Buyanova

\section{Linköping University Post Print}

\section{Tweet}

N.B.: When citing this work, cite the original article.

Original Publication:

Jan Eric Stehr, Alexander Dobrovolsky, S. Sukrittanon, Yanjin Kuang, C. W. Tu, Weimin Chen and Irina Buyanova, Optimizing GaNP Coaxial Nanowires for Efficient Light Emission by Controlling Formation of Surface and Interfacial Defects, 2015, Nano letters (Print), (15), 1, 242-247.

http://dx.doi.org/10.1021/n1503454s

Copyright: American Chemical Society http://pubs.acs.org/

Postprint available at: Linköping University Electronic Press http://urn.kb.se/resolve?urn=urn:nbn:se:liu:diva-113960 


\section{Optimizing GaNP coaxial nanowires for efficient light emission}

\section{by controlling formation of surface and interfacial defects}

Jan E. Stehr*†, Alexander Dobrovolsky†, Supanee Sukrittanon§, Yanjin Kuangł, Charles W. Tu\|, Weimin M. Chen†, and Irina A. Buyanova**, $†$

$†$ Department of Physics, Chemistry and Biology, Linköping University, 58183 Linköping, Sweden

$\S$ Graduate Program of Materials Science and Engineering, University of California, San Diego, La Jolla, California 92093, USA

† Department of Physics, University of California, San Diego, La Jolla, California 92093, USA

|| Department of Electrical and Computer Engineering, University of California, San Diego, La Jolla, California 92093, USA

\section{KEYWORDS}

GaNP, nanowires, core/shell structures, defects, light emission, ODMR

\section{ABSTRACT}

We report on identification and control of important non-radiative recombination centers in GaNP coaxial nanowires (NWs) grown on Si substrates, in an effort to significantly increase light emitting efficiency of these novel nanostructures promising for a wide variety of 
optoelectronic and photonic applications. A point defect complex, labeled as DD1 and consisting of a $\mathrm{P}$ atom with a neighboring partner aligned along a crystallographic $<111>$ axis, is identified by optically detected magnetic resonance as a dominant non-radiative recombination center that resides mainly on the surface of the NWs and partly at the hetero-interfaces. The formation of DD1 is found to be promoted by the presence of nitrogen and can be suppressed by reducing the strain between the core and shell layers, as well as by protecting the optically active shell by an outer passivating shell. Growth modes employed during the NW growth are shown to play a role. Based on these results, we identify the $\mathrm{GaP} / \mathrm{GaN}_{\mathrm{y}} \mathrm{P}_{1-\mathrm{y}} / \mathrm{GaN}_{\mathrm{x}} \mathrm{P}_{1-\mathrm{x}}(\mathrm{x}<\mathrm{y})$ core/shell/shell $\mathrm{NW}$ structure, where the $\mathrm{GaN}_{\mathrm{y}} \mathrm{P}_{1-\mathrm{y}}$ inner shell with the highest nitrogen content serves as an active light-emitting layer, as the optimized and promising design for efficient light emitters based on GaNP NWs. 
One-dimensional nanowire (NW) structures from III-V semiconductors are currently attracting an increasing research interest as a building block for a wide variety of optoelectronic and photonic applications ranging from light harvesting and photo-detection to light emitting [16]. A novel III-V material system that has a great potential for these applications is GaNP. Adding nitrogen to $\mathrm{GaP}$ minimizes, or even fully eliminates, lattice mismatch to $\mathrm{Si}$, advantageous for 3D integration of III-V materials with the mature microelectronic technologies based on $\mathrm{Si}[7,8]$. Also, a strong anticrossing interaction between the band states and nitrogen states leads to the giant bowing in the bandgap energy $[9,10]$ and transforms the band gap character from an indirect bandgap in GaP to a quasi-direct band one in GaNP $[10,11]$. This increases light emission efficiency of the alloy and allows one to tune its band gap energy from 1.2 to $2.2 \mathrm{eV}$ [12], i.e. to cover the amber spectral range. The latter is currently difficult to realize using other material systems. Moreover, $\mathrm{N}$-induced splitting of the conduction band states into two subbands makes GaNP suitable for applications in intermediate band solar cells that are predicted [13] to have quantum efficiency substantially exceeding the Shockley-Queisser limit [14] for a single junction. Recently we have shown that these functionalities can be further enhanced in the case of nanowires. For example, the light harvesting efficiency of GaNP NW arrays can be improved via energy upconversion caused by two-step two photon absorption [15]. Also, alloying with nitrogen allows one to realize nano-scale light sources that emit light linearly polarized perpendicularly to the wire axis even in zinc blende nanowires of various diameters [16]. These attractive features are combined with the fact that GaNP NWs can be grown without using gold droplets as catalysts, which could be crucial for integration of GaNP with Si. This is because gold introduces detrimental deep states in $\mathrm{Si}$ and is, therefore, excluded from using in $\mathrm{Si}$ 
and complementary-metal-oxide-semiconductor (CMOS) compatible technological processes [8]. It was also shown to degrade the optoelectronic properties of III-V NWs [17].

Unfortunately, alloying with nitrogen often degrades the material quality and leads to severe non-radiative carrier recombination [18]. Chemical identity of the involved defects was extensively studied for planar GaNP [18-20] where the non-radiative recombination was shown to originate from point defects formed in bulk regions of the alloy. In the case of NWs, however, increasing surface-to-volume ratio raises importance of recombination processes via surface states $[17,21,22]$, however, the origin of these states is so far poorly understood. Existing reports on defect formation in III-V NWs and associated core/shell nanostructures were primarily focused on extended defects [23-26], which seem to be of limited importance in carrier recombination. Detailed studies of point and surface defects in GaNP-based NWs, and in 1D structures in general, remain scarce $[27,28]$.

In this work we employ optically detected magnetic resonance (ODMR) spectroscopy complemented by $\mu$-photoluminescence ( $\mu$-PL) and time-resolved PL studies to identify dominant point defects that affect radiative efficiency of $\mathrm{Ga}(\mathrm{N}) \mathrm{P} / \mathrm{GaNP}$ core/shell NWs grown on Si substrates, with the aim to unveil an optimum structural design for efficient light emitters. In order to investigate the impact of nitrogen content, growth mechanisms and structural design on the defect formation, three types of structures were studied: (A) - Ga(N)P NWs grown via the vapor-liquid solid (VLS) mechanism; (B) - $\mathrm{GaP} / \mathrm{GaN}_{\mathrm{y}} \mathrm{P}_{1-\mathrm{y}}$ and $\mathrm{GaN}_{\mathrm{x}} \mathrm{P}_{1-\mathrm{x}} / \mathrm{GaN}_{\mathrm{y}} \mathrm{P}_{1-\mathrm{y}}(\mathrm{x}<\mathrm{y})$ core/shell NWs with the VLS-grown core and the shell layer formed via the step-mediated growth; and (C) $-\mathrm{GaP} / \mathrm{GaN}_{\mathrm{y}} \mathrm{P}_{1-\mathrm{y}} / \mathrm{GaN}_{\mathrm{x}} \mathrm{P}_{1-\mathrm{x}}(\mathrm{x}<\mathrm{y})$ core/shell/shell $\mathrm{NWs}$ with an additional passivating outer shell grown via the VLS mechanism. (See the Methods section for a more detailed description of the structures). Illustrations of the studied structures are depicted in Figure 
1 together with representative scanning electron microscopy (SEM) images of the studied NW arrays. The light (orange online) areas in Figure 1a indicate the optically active region of the NWs with the highest nitrogen composition, that is, the outer $\mathrm{GaN}_{\mathrm{y}} \mathrm{P}_{1-\mathrm{y}}$ shell in the type-B structures and the inner $\mathrm{GaN}_{\mathrm{y}} \mathrm{P}_{1-\mathrm{y}}$ shell in the type-C NWs. All NWs have a hexagonal crosssection and are vertically aligned on (111) Si substrates. They have predominantly zinc blende crystal structure with minor inclusions of wurtzite phases.

(a)
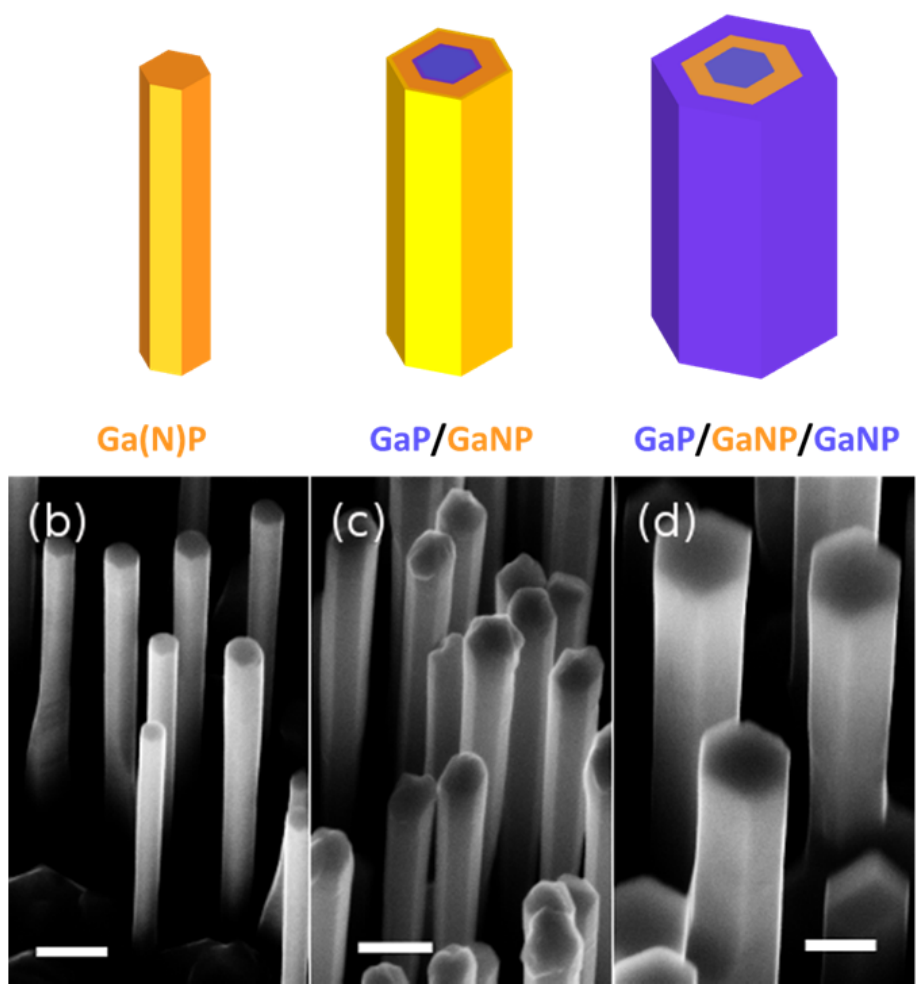

Figure 1: (a) Schematic illustrations of the studied NW structures. Light (orange online) areas are optically active regions of the NWs with the highest nitrogen content. Representative SEM images of arrays of the Ga(N)P NWs (b), GaP/GaNP core/shell NWs (c) and GaP/GaN $\mathrm{N}_{\mathrm{y}} \mathrm{P}_{1}$ ${ }_{\mathrm{y}} / \mathrm{GaN}_{\mathrm{x}} \mathrm{P}_{1-\mathrm{x}}$ core/shell/shell NWs (d) grown on (111) Si substrates. The scale bar displayed in (b)(d) is $300 \mathrm{~nm}$. 
To investigate the formation of point defects in the NWs we employed the ODMR technique, which is known to be among the most powerful and versatile experimental methods for defect identification $[29,30]$. The ODMR signals were measured by monitoring the near-band-edge emission from the GaNP alloy caused by the recombination of excitons trapped at various Nrelated centers [31], as shown in Figure 2a. All investigated structures were found to exhibit the same ODMR signal, as shown by the open circles in Figure $2 \mathrm{c}$ and $2 \mathrm{~d}$, taking as an example the $\mathrm{GaP} / \mathrm{GaNP}$ core/shell NWs. It contains two overlapping peaks with a line width of approximately $25 \mathrm{mT}$. The ODMR signal is negative, corresponding to a microwave induced decrease of the PL intensity, which implies that the responsible defect acts as a recombination center competing with the monitored PL [29]. To reveal its chemical identity, we performed an analysis of the ODMR spectra using the following Spin-Hamiltonian that includes an electron Zeeman term and a central hyperfine interaction term:

$$
\mathcal{H}=\mu_{B} \boldsymbol{B} \boldsymbol{g} \boldsymbol{S}+\boldsymbol{S A I}
$$

Here $\mathbf{B}$ denotes an external magnetic field, $\mathbf{g}$ and $\mathbf{A}$ are the electron g-tensor and the hyperfine interaction tensor, respectively. Since the observed splitting between the ODMR peaks does not depend on the two microwave frequencies used in the ODMR experiments and therefore the strength of the magnetic field required to satisfy magnetic resonance conditions, see Figure $2 \mathrm{c}$ and $2 \mathrm{~d}$, this doublet structure reflects a resolved hyperfine interaction between an unpaired localized electron spin $(S=1 / 2)$ and a nuclear spin $I=1 / 2$ with $100 \%$ natural abundance, i.e. a ${ }^{31} \mathrm{P}$ nucleus. The spin-Hamiltonian parameters of the center can then be determined as $\mathrm{g}_{\|}=2.002, \mathrm{~g}_{\perp}$ $=2.013, \mathrm{~A}_{\|}=330 \times 10^{-4} \mathrm{~cm}^{-1}$ and $\mathrm{A}_{\perp}=130 \times 10^{-4} \mathrm{~cm}^{-1}$. The simulated ODMR spectra are 
shown by the solid line (red online) in Figure $2 \mathrm{c}$ and $2 \mathrm{~d}$, which are in very good agreement with the experimental data. The obtained spin-Hamiltonian parameters are in fact identical to those of the so-called DD1 defect, which was previously observed by Dagnelund et al. in planar GaP/GaNP structures grown on (001)-oriented GaP substrates [32] and by Dobrovolsky et al. in GaP/GaNP NWs grown on (111)-oriented Si substrates [28]. DD1 was identified as an interfacial defect complex, which consists of a $\mathrm{P}_{\mathrm{Ga}}$ antisite (or a $\mathrm{P}_{\mathrm{i}}$ interstitial) aligned with a neighboring partner (possibly a nitrogen atom) along a $<111>$ crystallographic direction. In planar structures the defect resides at the GaNP side of the GaP/GaNP interface [32]. In the case of GaNP-based NWs, however, the exact location of DD1 remains unknown. Here, several defect locations, which define orientations of the DD1 principal axis in the lattice, are possible and were considered during the simulations. These include: (i) the interfaces between the GaNP shell and the $\mathrm{GaP}$ core in the type- $\mathrm{B}$ and $-\mathrm{C}$ structures; (ii) the interface between the $\mathrm{GaP}$ seed region and the GaNP NW for the type-A structures, and (iii) the surfaces of the NWs including the (111) top surface and (0-11), (10-1), (1-10), (01-1), (-101) and (-110) side facets. A possible DD1 configuration at the NW surfaces is schematically illustrated in Figure 2b. Unfortunately, due to the broad line width of the observed ODMR signal the most probable location of DD1 in the NWs cannot be singled out solely based on the simulation results. Such information is imperative, however, for designing strategies on how to suppress the defect formation during the growth. 

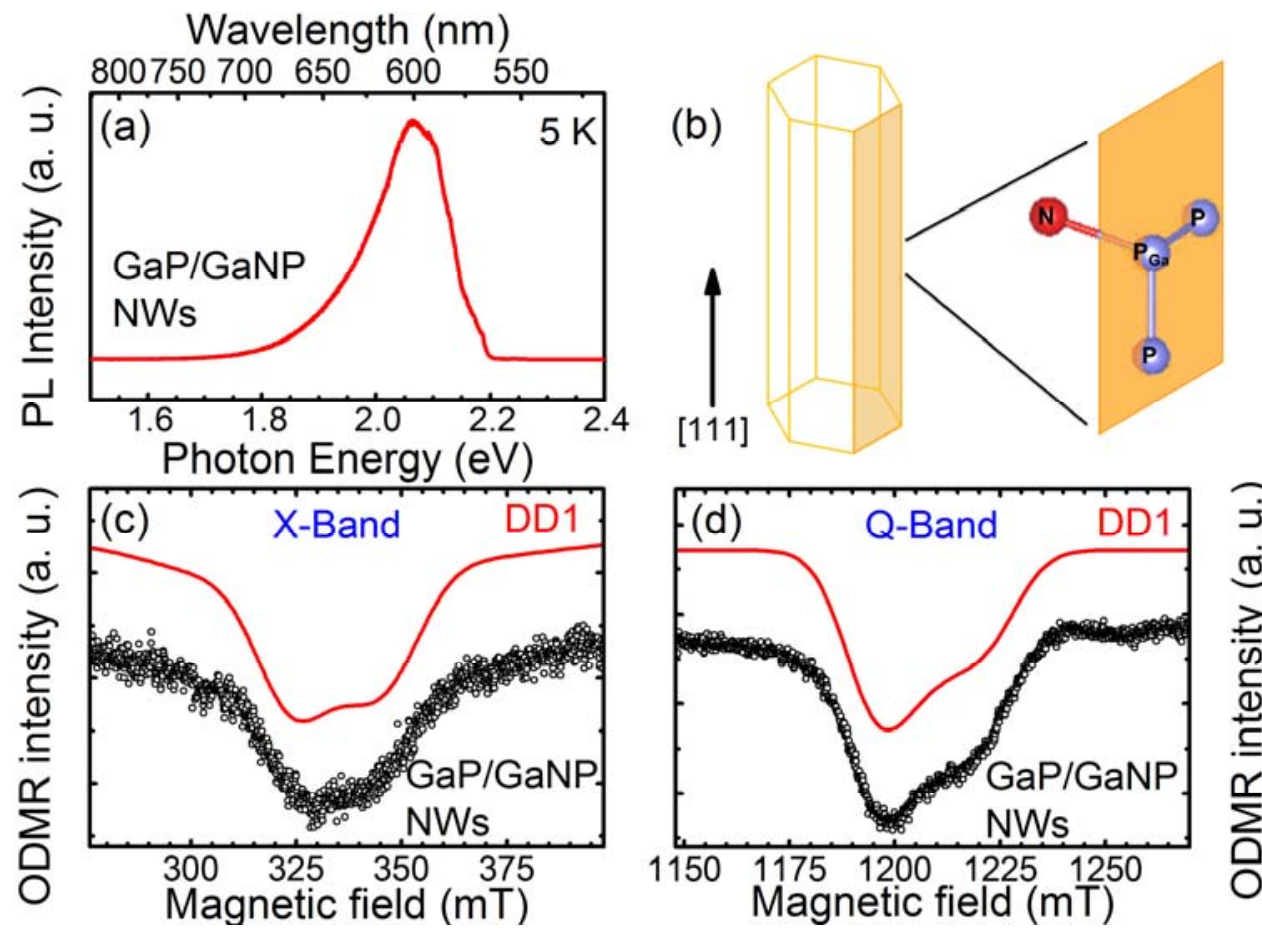

Figure 2: (a) A representative PL spectrum measured at $5 \mathrm{~K}$ from the GaP/GaNP NW array. (b) A model illustrating a possible configuration of the DD1 defect on the NW surface, taking as an example a $\mathrm{P}_{\mathrm{Ga}}$ antisite forming a complex with a partnering nitrogen atom. (c) and (d) ODMR spectra of the GaP/GaNP NWs measured at $4 \mathrm{~K}$ (the open circles) at X- band (9.4 GHz) and Qband (34 GHz), respectively. The solid lines are the simulated spectra of DD1 using the spinHamiltonian parameters given in the text.

In order to gain an in-depth understanding of the processes responsible for the DD1 formation and also to single out the most efficient ways to minimize it during the growth, we have performed detailed defect studies of the GaNP NWs as a function of growth conditions and structural design. Here, the main factors that were considered include (i) nitrogen composition in the alloy, (ii) the growth mode utilized for the GaNP growth; (iii) presence of strain in the 
optically active GaNP layer caused by lattice mismatch between GaP and GaNP in GaP/GaNP core/shell structures; and (iv) surface passivation. The main results of these studies are summarized below.

(i) Effects of nitrogen content. We first evaluate the impact of the nitrogen content on the DD1 formation. For these purposes the type- $\mathrm{A} \mathrm{Ga}_{1-\mathrm{x}} \mathrm{N}_{\mathrm{x}} \mathrm{P}$ NWs with $x$ ranging from 0 to 0.006 were studied. Figure 3 compares the ODMR spectrum from the GaP NWs (1) with that from the GaNP NWs (2). One notices that the DD1 signal can only be detected in the N-containing structures and its intensity increases with increasing $x$ - see the inset in Figure 3 where the dependence of the DD1 ODMR signal intensity on the nitrogen content is shown. These results imply that the DD1 formation in the NWs is largely facilitated by the presence of nitrogen, consistent with the previous results for planar structures [32]. Two possible reasons could account for this behavior: (i) a nitrogen atom is directly involved as a partner of the DD1 defect complex; and (ii) the presence of nitrogen significantly lowers the formation energy of DD1, e.g. due to strain effect or local lattice distortion without being directly involved in the defect complex. Though none of these possibilities can be excluded in the present study due to a lack of a resolved hyperfine splitting from the neighboring atom, the first option seems to be more likely. This is because we could not detect the DD1 signal from the N-free GaP NWs independent of the employed growth conditions such as V/III incorporation ratios and substrate temperatures. The fact that this interfacial defect is formed in the GaNP NWs also suggests that DD1 may be formed on the NW surface, since the type-A wires have only one (111) interface with the GaP seed region that has a substantially (i.e. by 50 times) smaller area than the NW sidewall surfaces. Further arguments in favor of this conclusion will be provided below. 


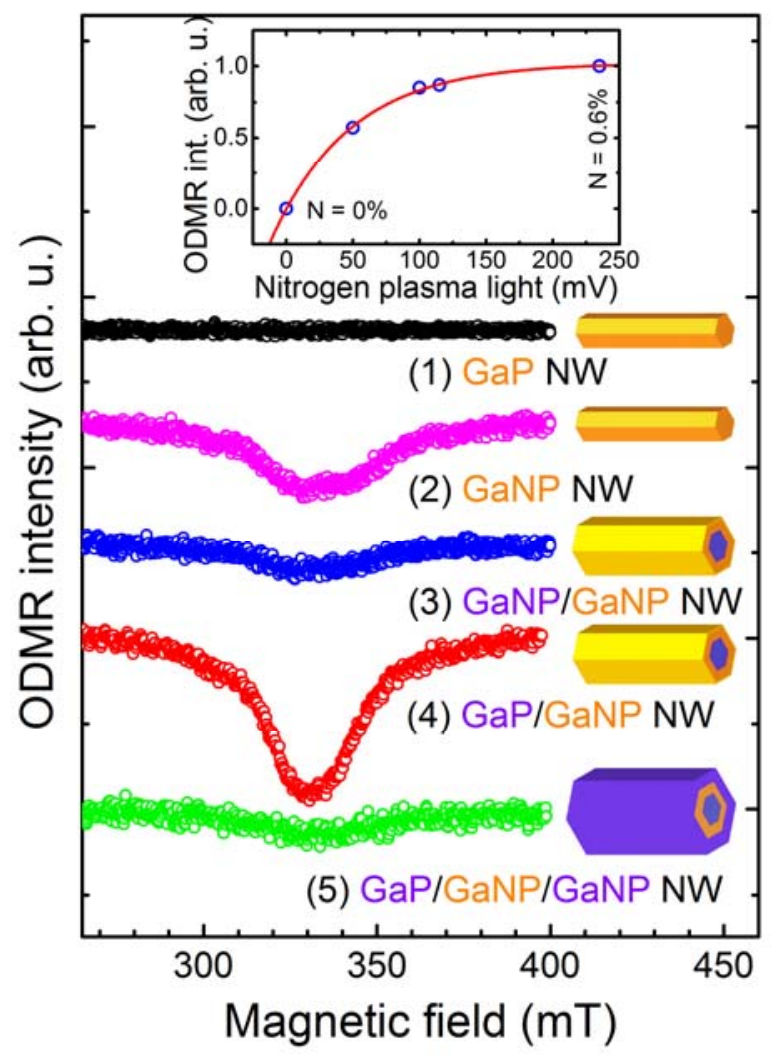

Figure 3: ODMR spectra from (1) the GaP NWs, (2) GaNP NWs, (3) $\mathrm{GaN}_{\mathrm{x}} \mathrm{P}_{1-\mathrm{x}} / \mathrm{GaN}_{\mathrm{y}} \mathrm{P}_{1-\mathrm{y}} \mathrm{NWs}$, (4) $\mathrm{GaP} / \mathrm{GaN}_{\mathrm{y}} \mathrm{P}_{1-\mathrm{y}} \mathrm{NWs}$ and (5) $\mathrm{GaP} / \mathrm{GaN}_{\mathrm{y}} \mathrm{P}_{1-\mathrm{y}} / \mathrm{GaN}_{\mathrm{x}} \mathrm{P}_{1-\mathrm{x}} \mathrm{NWs}$, together with illustrations of the corresponding NW structures. The inset shows the dependence of the DD1 ODMR signal intensity on the nitrogen content in the type-A Ga(N)P NWs. The solid line is a guide to the eye.

(ii) Effects of the growth modes. In the case of NWs, the growth of GaNP alloys can proceed either through VLS or step-mediated mechanisms [33]. Effects of the growth modes on the defect formation can be analyzed by comparing the ODMR signal strength between the type-A $\mathrm{GaN}_{\mathrm{y}} \mathrm{P}_{1-\mathrm{y}} \mathrm{NWs}$ and the type- $\mathrm{GaN}_{\mathrm{x}} \mathrm{P}_{\mathrm{x}} / \mathrm{GaN}_{\mathrm{y}} \mathrm{P}_{1-\mathrm{y}}(\mathrm{x}<\mathrm{y})$ core/shell structures with the same nitrogen composition $\mathrm{y}$ in the optically active layer. The corresponding ODMR spectra are 
shown by the curves (2) and (3) in Figure 3, respectively, taking as an example NWs with $y \sim 0.6$ $\%$. Apparently, the intensity of the DD1 ODMR signal is substantially reduced when the growth mode of the optically active GaNP region was changed from VLS in the type-A NWs (curve (2)) to the step-mediated growth of the shell layer in the type-B structure (curve (3)). The observed suppression of the defect formation can be attributed to the reduction of the growth rate from about $150 \mathrm{~nm} / \mathrm{min}$ during the axial VLS growth of the GaNP NWs [34] down to about 1.8 $\mathrm{nm} /$ min during the radial growth of the GaNP shell [33], which results in a higher material quality.

(iii) Effects of strain. In principle, the defect formation in semiconductor materials can be affected by strain due to a change in defect formation energy [35-37]. In order to evaluate importance of this effect in the studied structures, we performed comparable ODMR studies of the core/shell NWs with the same optically active $\mathrm{GaN}_{\mathrm{y}} \mathrm{P}_{1-\mathrm{y}}$ shell but different core materials. A substantial enhancement of the DD1 signal was observed in the $\mathrm{GaP} / \mathrm{GaN}_{\mathrm{y}} \mathrm{P}_{1-\mathrm{y}}$ core/shell NWs as compared with the $\mathrm{GaN}_{\mathrm{x}} \mathrm{P}_{\mathrm{x}} / \mathrm{GaN}_{\mathrm{y}} \mathrm{P}_{1-\mathrm{y}}$ structures - see Figure 3, where the corresponding ODMR spectra are shown as curves (4) and (3), respectively. Since the $\mathrm{GaN}_{\mathrm{y}} \mathrm{P}_{1-\mathrm{y}}$ shell layers in both structures have the same nitrogen composition and were grown under identical conditions, this result suggests that the presence of strain between the $\mathrm{GaP}$ core and the $\mathrm{GaN}_{\mathrm{y}} \mathrm{P}_{1-\mathrm{y}}$ shell promotes the formation of DD1. In principle, this fact could be considered to be in favor of the core/shell interface as a likely location for DD1. We need to note, however, that the thickness of the $\mathrm{GaN}_{\mathrm{y}} \mathrm{P}_{1-\mathrm{y}}$ shell is only $\sim 50 \mathrm{~nm}$, which is well below the critical thickness of GaNP [38]. This means that the strain will not be relaxed at the hetero-interface and may also influence formation of the defect on the $\mathrm{GaN}_{\mathrm{y}} \mathrm{P}_{1-\mathrm{y}}$ outer surfaces. 
(iv) Effects of surface passivation. In order to examine the possibility of the DD1 defect being located at the outer surfaces of the NWs, we have fabricated $\mathrm{GaP} / \mathrm{GaN}_{\mathrm{y}} \mathrm{P}_{1-\mathrm{y}} / \mathrm{GaN}_{\mathrm{x}} \mathrm{P}_{1-\mathrm{x}}$ core/shell/shell NWs with an outer passivating shell of $\mathrm{GaN}_{\mathrm{x}} \mathrm{P}_{1-\mathrm{x}}$. The reason for choosing $\mathrm{GaN}_{\mathrm{x}} \mathrm{P}_{1-\mathrm{x}}$ with $x<y$ as a passivating layer is as follows. This design allows us to minimize detrimental lattice mismatch with the active region, while maintaining carrier localization in the active $\mathrm{GaN}_{\mathrm{y}} \mathrm{P}_{1-\mathrm{y}}$, due to fast trapping of carriers from the passivating shell with a larger bandgap. It is found that after adding the outer shell the DD1 intensity is drastically reduced, by about one order of magnitude, as can be seen from the ODMR spectra (4) and (5) in Figure 3. This provides unambiguous experimental evidence that the majority of the DD1 defects are formed at the NW surfaces. Lowering of the defect formation energy in the near-surface region was also reported for N-related defects in $\mathrm{ZnO}$ nanostructures [39].

We can now analyze the importance of the identified surface defect in carrier recombination at room temperature (RT), which is crucial to practical applications. Based on the negative sign of the DD1 ODMR signal, the defect center participates in recombination processes that compete with the radiative recombination process giving rise to the near-band-edge $\mathrm{PL}$ of $\mathrm{GaN}_{\mathrm{y}} \mathrm{P}_{1-\mathrm{y}}$. Suppression of its formation in the multi-shell NWs is, therefore, expected to significantly enhance their radiative efficiency, provided that DD1 acts as an important recombination center. To prove the latter, we performed $\mu$-PL experiments on single $\mathrm{GaP} / \mathrm{GaN}_{\mathrm{y}} \mathrm{P}_{1-\mathrm{y}}$ core/shell and single $\mathrm{GaP} / \mathrm{GaN}_{\mathrm{y}} \mathrm{P}_{1-\mathrm{y}} / \mathrm{GaN}_{\mathrm{x}} \mathrm{P}_{1-\mathrm{x}}$ core/shell/shell NWs. The RT PL spectra from both structures contain a broad emission band (see Figure 4a) that originates from the optically active $\mathrm{GaN}_{\mathrm{y}} \mathrm{P}_{1-\mathrm{y}}$ region and is caused by the recombination of excitons bound to different N-related centers [28]. From Figure $4 \mathrm{a}$ it is obvious that the surface passivation of the active region and, therefore, suppression of the DD1 formation, leads to a drastic enhancement of the emission intensity. To 
confirm that the data acquired on a single NW are representative for the whole NW array, we measured statistical behavior of about $50 \mathrm{NWs}$ from each type of the structures. The RT PL intensity is found to follow a Gaussian distribution which peaks at around 20 and 210 counts/sec for the $\mathrm{GaP} / \mathrm{GaN}_{\mathrm{y}} \mathrm{P}_{1-\mathrm{y}} \mathrm{NWs}$ and $\mathrm{GaP} / \mathrm{GaN}_{\mathrm{y}} \mathrm{P}_{1-\mathrm{y}} / \mathrm{GaN}_{\mathrm{x}} \mathrm{P}_{1-\mathrm{x}} \mathrm{NWs}$, respectively - see Figure $4 \mathrm{~b}$. These values are in good agreement with the PL data measured from the corresponding NW arrays. The origin of the observed enhancement in the PL intensity can be further clarified from transient PL measurements. The transient PL images measured from the arrays of $\mathrm{GaP} / \mathrm{GaN}_{\mathrm{y}} \mathrm{P}_{1-}$ ${ }_{y} / \mathrm{GaN}_{\mathrm{x}} \mathrm{P}_{1-\mathrm{x}} \mathrm{NWs}$ and $\mathrm{GaP} / \mathrm{GaN}_{\mathrm{y}} \mathrm{P}_{1-\mathrm{y}} \mathrm{NWs}$ are shown in Figure $4 \mathrm{c}$ and Figure $4 \mathrm{~d}$, respectively. One observes that the PL decay is substantially slower in the former, as is also obvious from Figure 4e, where the PL decays from both NWs arrays are shown. This slower PL decay can be explained by a reduction of non-radiative carrier recombination in the multi-shell structure. Indeed, the decay time $(\tau)$ of radiative transitions is determined by combined contributions of radiative and non-radiative recombination processes so that $\frac{1}{\tau}=\frac{1}{\tau_{r}}+\frac{1}{\tau_{n r}}$, where $\tau_{r}$ and $\tau_{n r}$ denote the radiative and non-radiative lifetimes, respectively. Since the radiative lifetime is intrinsic to the N-related emission, the prolongation of its decay in the multi-shell structure combined with the observed increase in the PL intensity provide compelling evidence that surface passivation of the active region efficiently suppresses the non-radiative recombination mediated by DD1. The optimized core/shell/shell NWs have an excellent optical quality that is comparable to that of the state-of-the-art GaNP epilayers capped with GaP. This is evident from the practically identical RT PL decays in these structures (see Fig. 2e, where the PL decay from the GaNP epilayer is shown by the dotted line) and is further supported by their similar internal quantum efficiencies $\eta_{\text {int }}$, i.e. $0.8 \%$ (for $\mathrm{NWs)} \mathrm{and} 0.9 \%$ (for epilayers). The latter were 
determined in the same way as described in reference 41 . It is interesting to note that these values are comparable to that of $\mathrm{AlGaN} / \mathrm{GaN}$ quantum wells $\left(\eta_{\text {int }}=1.2 \%\right)[41]$.

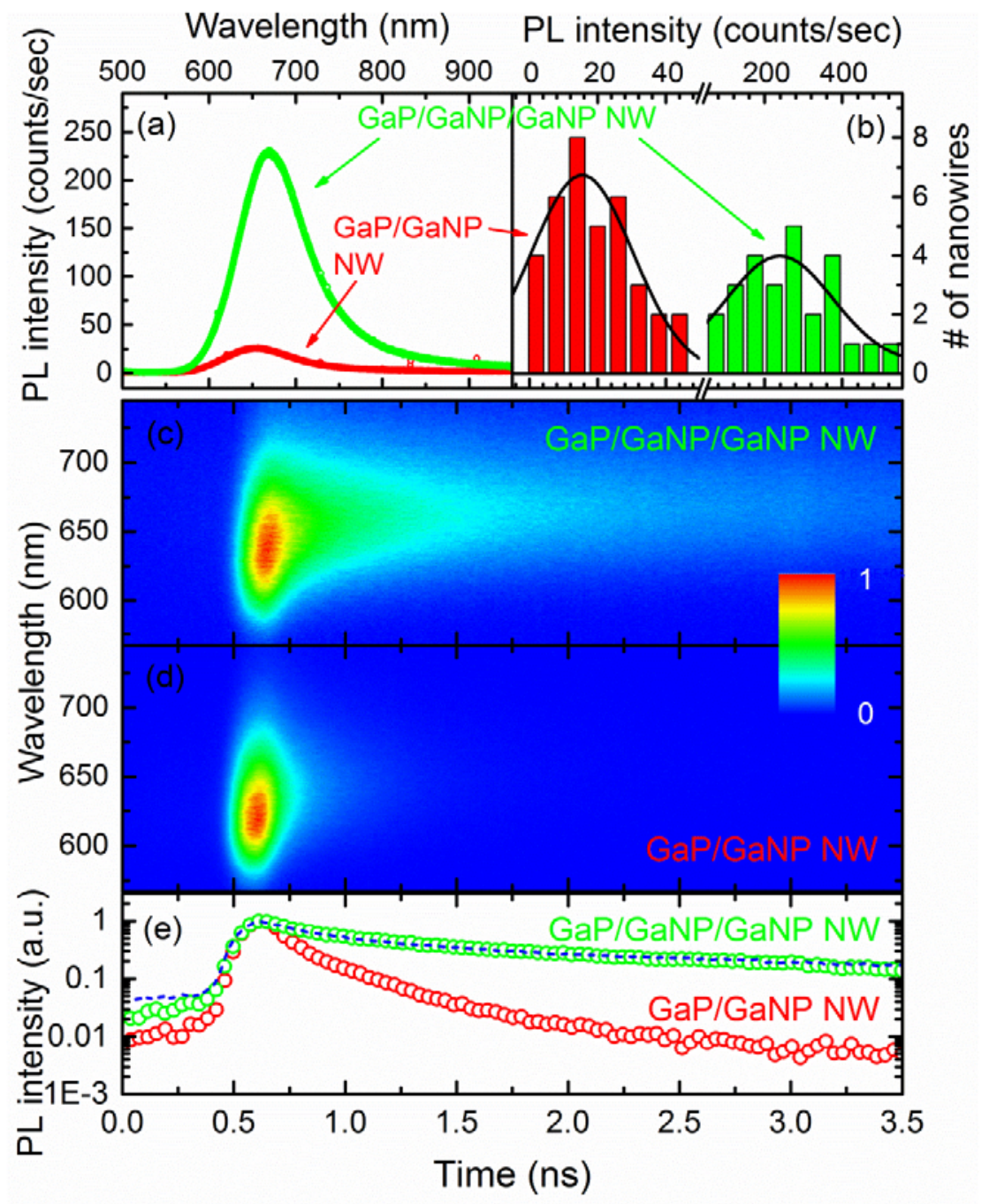

Figure 4: (a) Representative $\mu$-PL spectra from a single $\mathrm{GaP} / \mathrm{GaN}_{\mathrm{y}} \mathrm{P}_{1-\mathrm{y}}$ core/shell $\mathrm{NW}$ and a single $\mathrm{GaP} / \mathrm{GaN}_{\mathrm{y}} \mathrm{P}_{1-\mathrm{y}} / \mathrm{GaN}_{\mathrm{x}} \mathrm{P}_{1-\mathrm{x}}$ core/shell/shell NW with $\mathrm{y} \sim 0.6 \%$, as estimated using the band anticrossing model $[10,40]$. (b) Statistical distributions of the PL intensity from individual $\mathrm{GaP} / \mathrm{GaNP}$ core/shell NWs and $\mathrm{GaP} / \mathrm{GaN}_{\mathrm{y}} \mathrm{P}_{1-\mathrm{y}} / \mathrm{GaN}_{\mathrm{x}} \mathrm{P}_{1-\mathrm{x}}$ core/shell/shell NWs. (c) and (d) display transient PL images measured from $\mathrm{GaP} / \mathrm{GaN}_{\mathrm{y}} \mathrm{P}_{1-\mathrm{y}} / \mathrm{GaN}_{\mathrm{x}} \mathrm{P}_{1-\mathrm{x}}$ and $\mathrm{GaP} / \mathrm{GaN}_{\mathrm{y}} \mathrm{P}_{1-\mathrm{y}} \mathrm{NW}$ arrays, 
respectively. (e) The corresponding decays (symbols) of the PL intensity spectrally integrated within the $15 \mathrm{~nm}$ range around its peak position. The dotted line represents the PL decay measured from the reference $\mathrm{GaN}_{0.006} \mathrm{P}_{0.994}$ epilayer capped with GaP. The data in (c) - (e) are normalized to the same peak intensity for an easier comparison. All PL measurements were performed at RT.

In summary, by employing the ODMR technique complemented by cw- and transient PL studies we have identified the DD1 defect, the complex that involves a P atom at its core, as an important source of non-radiative recombination that deteriorates radiative efficiency of GaNPbased NWs grown on Si substrates. By evaluating optical and defect properties of various GaNP and $\mathrm{Ga}(\mathrm{N}) \mathrm{P} / \mathrm{GaNP}$ core/multi-shell $\mathrm{NW}$ structures, we have also shown that the major factors affecting the formation of this harmful defect during the growth include nitrogen content, growth mode of the GaNP layer and the presence of strain. The defect formation is concluded to predominantly occur on the surface of the GaNP layer but could be drastically suppressed by adding an outer passivating shell of GaNP with a lower nitrogen content. Based on these results, the optimized design of GaNP NWs leading to a high efficiency of light emission is identified as being the $\mathrm{Ga}(\mathrm{N}) \mathrm{P} / \mathrm{GaNP} / \mathrm{GaNP}$ core/shell/shell structure where the active inner shell with the highest nitrogen content is grown via the step-mediated mode and has passivated surfaces. Our findings, therefore, provide a useful guideline for designing efficient nanoscale light emitters based on GaNP alloys and emphasize the importance of suppressing formation of the detrimental point defects in NW structures by optimizing growth conditions and structural design. We note that the suggested radial core/multi-shell design provides an additional freedom to independently 
control composition, doping and size of core and shell layers, thereby tuning the band offset across the radial hetero-interfaces to create an efficient radial confinement or to enhance the separation of carriers.

\section{Methods}

All the NW structures studied in this work were grown on (111)-oriented Si substrates by gassource molecular beam epitaxy (GS MBE) using Ga droplets as a catalyst $[33,34]$. The following types of NW structures were investigated: (A) $\mathrm{GaP}$ and $\mathrm{GaN}_{\mathrm{y}} \mathrm{P}_{1-\mathrm{y}} \mathrm{NWs}$ with diameters ranging from 80 to $100 \mathrm{~nm}$; (B) $\mathrm{GaP} / \mathrm{GaN}_{\mathrm{y}} \mathrm{P}_{1-\mathrm{y}}$ core/shell and $\mathrm{GaN}_{\mathrm{x}} \mathrm{P}_{1-\mathrm{x}} / \mathrm{GaN}_{\mathrm{y}} \mathrm{P}_{1-\mathrm{y}}(\mathrm{x}<\mathrm{y})$ core/shell NWs having a 50-nm thick shell layer; and (C) $\mathrm{GaP} / \mathrm{GaN}_{\mathrm{y}} \mathrm{P}_{1-\mathrm{y}} / \mathrm{GaN}_{\mathrm{x}} \mathrm{P}_{1-\mathrm{x}}(\mathrm{x}<\mathrm{y})$ core/shell/shell NWs with an outer passivating shell of $30-80 \mathrm{~nm}$ in thickness. To initiate the NW growth for the type-A structures, a seed $\mathrm{GaP}$ region was grown prior to igniting a nitrogen plasma [34]. The type-A GaP and GaNP NWs were grown by the VLS mechanism with substrate temperatures $\mathrm{T}_{\text {sub }}$ of $580-600{ }^{\circ} \mathrm{C}$ and $615{ }^{\circ} \mathrm{C}$, respectively. The V/III incorporation ratio was kept at around 1.5 -2.0 during the GaP growth and was increased to 2.5 after a nitrogen plasma was ignited for the growth of GaNP. The same growth conditions were used for the core layers in (B) and (C) structures. The GaNP shells were fabricated via the step-mediated growth with a lower substrate temperature $\mathrm{T}_{\text {sub }}$ of $450-510{ }^{\circ} \mathrm{C}$ and a $\mathrm{V} / \mathrm{III}$ incorporation ratio of $3.5-4.5$. The nitrogen composition in the shell layers was varied by changing the power of the rf-plasma and the nitrogen flux. It was estimated by comparing the room-temperature PL data with the band anticrossing model described in references 10 and 40. In all types of the studied structures, the NWs display a uniform size distribution with an average axial length of approximately $2-3 \mu \mathrm{m}$. A detailed description of the growth procedure can be found in refs. 33 and 34 . 
The ODMR experiments were performed at $4 \mathrm{~K}$ with a modified ESR spectrometer working at the X-band $(\sim 9.4 \mathrm{GHz})$ and Q-band ( $\sim 34 \mathrm{GHz})$. ODMR signals were measured as a change of the integrated PL intensity detected within the visible spectral range of $420-1000 \mathrm{~nm}$ under magnetic resonance conditions. The PL was excited using the $532 \mathrm{~nm}$ line of a solid-state laser and detected by a Si detector. In order to avoid contributions of laser leakage in the detected PL signal, appropriate long-pass and short-pass optical filters were inserted in the detection and excitation path, respectively.

$\mu$-PL spectroscopy of individual NWs and NW arrays was performed at $5 \mathrm{~K}$ and RT by using a Horiba Jobin Yvon HR800 spectrometer equipped with a CCD detector. The excitation light, the $445 \mathrm{~nm}$ line of a diode laser or the $532 \mathrm{~nm}$ line of a solid-state laser, was focused onto the sample using a 50x objective lens with $\mathrm{NA}=0.5$, which was also used for collecting the emitted PL. In order to access optical properties of individual nanowires, the wires were mechanically transferred onto another Si substrate. Time-resolved PL measurements were carried out at RT by using a pulsed Ti:sapphire laser with a pulse duration of 2 ps and a repetition rate of $76 \mathrm{MHz}$. The transient PL signals were detected by a streak camera combined with a $0.5 \mathrm{~m}$ single grating monochromator.

\section{AUTHOR INFORMATION}

\section{Corresponding Authors}

*E-mail: janst@ifm.liu.se,

**E-mail: iribu@ifm.liu.se

\section{Author Contributions}


The manuscript was written through contributions from all authors. All authors have given approval to the final version of the manuscript.

\section{Notes}

The authors declare no competing financial interest.

\section{ACKNOWLEDGMENT}

Financial support by the Swedish Research Council (grant no. 621-2010-3815) is greatly appreciated. The nanowire growth is supported by the U.S. National Science Foundation under Grants \# DMR-0907652 and DMR-1106369. S.S. is partially funded by a Royal Government of Thailand Scholarship.

\section{REFERENCES}

(1) Wang, J.; Gudiksen, M. S.; Duan, X.; Cui, Y.; Lieber, C. M. Science 2001, 293, 1455 1457.

(2) Duan, X.; Huang, Y.; Cui, Y.; Wang, J.; Lieber, C. M. Nature 2001, 409, 66-69.

(3) Gudiksen, M. S.; Lauhon, L. J.; Wang, J.; Smith, D. C.; Lieber, C. M. Nature 2002, 415, 617-620.

(4) Tomioka, K.; Motohisa, J.; Hara, S.; Hiruma, K.; Fukui, T. Nano Lett. 2010, 10, 16391644.

(5) Chen, R.; Tran, T. D.; Ng, K. W.; Ko, W. S.; Chuang, L. C.; Sedgwick, F. G.; ChangHasnain, C. Nat. Photonics 2011, 5, 170-175.

(6) Wallentin, J.; Anttu, N.; Asoli, D.; Huffman, M.; Aberg, I.; Magnusson, M. H.; Siefer, G.; Fuss-Kailuweit, P.; Dimroth, F.; Witzigmann, B.; Xu, H. Q.; Samuelson, L.; Deppert, K.; Borgström, M. T. Science 2013, 339, 1057-1060. 
(7) Mårtensson, T.; Svensson, C. P. T.; Wacaser, B. A.; Larsson, M. W.; Seifert, W.; Deppert, K.; Gustafsson, A.; Wallenberg, L. R.; Samuelson, L. Nano Lett. 2004, 4, 1987-1990.

(8) Conesa-Boj, S.; Kriegner, D.; Han, X.-L.; Plissard, S.; Wallart, X.; Stangl, J.; Fontcuberta i Morral, A.; Caroff, P. Nano Lett. 2014, 14, 326-332.

(9) Kent, P. R. C.; Zunger, A. Phys. Rev. B 2001, 64, 115208.

(10) Shan, W.; Walukiewicz, W.; Yu, K. M.; Wu, J.; Ager, J. W.; Haller, E. E.; Xin, H. P.; Tu, C. W. Appl. Phys. Lett. 2000, 76, 3251.

(11) Buyanova, I. A.; Pozina, G.; Bergman, J. P.; Chen, W. M.; Xin, H. P.; Tu, C. W. Appl. Phys. Lett. 2002, 81, 52.

(12) Bi, W. G.; Tu, C. W. Appl. Phys. Lett. 1996, 69, 3710.

(13) Luque A.; Martí A; Stanley C. Nature Photonics 2012, 6, 146.

(14) Shockley, W.; Queisser, H. J. J. Appl. Phys. 1961, 32, 510.

(15) Dobrovolsky, A.; Sukrittanon, S.; Kuang, Y.; Tu, C. W.; Chen, W. M.; Buyanova, I. A. Small 2014. (doi: 10.1002/smll.201401342)

(16) Filippov, S.; Sukrittanon, S.; Kuang, Y.; Tu, C.; Persson, P. O. Å.; Chen, W. M.; Buyanova, I. A. Nano Lett. 2014, 14, 5264-5269.

(17) Holm, J. V; Jørgensen, H. I.; Krogstrup, P.; Nygård, J.; Liu, H.; Aagesen, M. Nat. Commun. 2013, 4, 1498.

(18) Buyanova, I. A.; Chen, W. M.; Tu, C. W. J. Phys. Condens. Matter 2004, 16, S3027.

(19) Thinh, N.; Vorona, I.; Buyanova, I.; Chen, W.; Limpijumnong, S.; Zhang, S.; Hong, Y.; Xin, H.; Tu, C.; Utsumi, A.; Furukawa, Y.; Moon, S.; Wakahara, A.; Yonezu, H. Phys. Rev. B 2005, 71, 125209.

(20) Thinh, N.; Vorona, I. P.; Buyanova, I. A.; Chen, W. M.; Limpijumnong, S.; Zhang, S. B.; Hong, Y. G.; Tu, C. W., Phys. Rev. B 2004, 70, 121201.

(21) Hua, B.; Motohisa, J.; Kobayashi, Y.; Hara, S.; Fukui, T. Nano Lett. 2009, 9, 112-116.

(22) Jiang, N.; Parkinson, P.; Gao, Q.; Breuer, S.; Tan, H. H.; Wong-Leung, J.; Jagadish, C. Appl. Phys. Lett. 2012, 101, 023111.

(23) Algra, R. E.; Verheijen, M. A.; Feiner, L.-F.; Immink, G. G. W.; Theissmann, R.; van Enckevort, W. J. P.; Vlieg, E.; Bakkers, E. P. A. M. Nano Lett. 2010, 10, 2349-2356. 
(24) Borg, M.; Schmid, H.; Moselund, K. E.; Signorello, G.; Gignac, L.; Bruley, J.; Breslin, C.; Das Kanungo, P.; Werner, P.; Riel, H. Nano Lett. 2014, 14, 1914-1920.

(25) Grassman, T. J.; Carlin, J. a.; Galiana, B.; Yang, L.-M.; Yang, F.; Mills, M. J.; Ringel, S. A. Appl. Phys. Lett. 2013, 102, 142102.

(26) Grossklaus, K. A.; Banerjee, A.; Jahangir, S.; Bhattacharya, P.; Millunchick, J. M. J. Cryst. Growth 2013, 371, 142-147.

(27) Stehr, J. E.; Chen, S. L.; Filippov, S.; Devika, M.; Koteeswara Reddy, N.; Tu, C. W.; Chen, W. M.; Buyanova, I. A. Nanotechnology 2013, 24, 015701.

(28) Dobrovolsky, A.; Stehr, J. E.; Chen, S. L.; Kuang, Y. J.; Sukrittanon, S.; Tu, C. W.; Chen, W. M.; Buyanova, I. A. Appl. Phys. Lett. 2012, 101, 163106.

(29) Chen, W. M. Thin Solid Films 2000, 364, 45-52.

(30) Chen, W. M.; Monemar, B. Appl. Phys. A Solids Surfaces 1991, 53, 130-135.

(31) Buyanova, I. A.; Rudko, G. Y.; Chen, W. M.; Xin, H. P.; Tu, C. W. Appl. Phys. Lett. 2002, 80, 1740 .

(32) Dagnelund, D.; Vorona, I. P.; Vlasenko, L. S.; Wang, X. J.; Utsumi, A.; Furukawa, Y.; Wakahara, A.; Yonezu, H.; Buyanova, I. A.; Chen, W. M. Phys. Rev. B 2010, 81, 115334.

(33) Kuang Y. J.; Sukrittanon S.; Li, H.; Tu C. W. Appl. Phys. Lett. 2012, 100, 053108.

(34) Sukrittanon, S.; Dobrovolsky, A.; Kang, W.-M.; Jang, J.-S.; Kim, B.-J.; Chen, W. M.; Buyanova, I. A.; Tu, C. W.; Kuang, Y. J. Appl. Phys. Lett. 2014, 105, 072107.

(35) Appavoo, K.; Lei, D. Y.; Sonnefraud, Y.; Wang, B.; Pantelides, S. T.; Maier, S. A; Haglund, R. F. Nano Lett. 2012, 12, 780-786.

(36) Wang, B.; Puzyrev, Y.; Pantelides, S. T. Carbon N. Y. 2011, 49, 3983-3988.

(37) Klie, R. F.; Buban, J. P.; Varela, M.; Franceschetti, A.; Jooss, C.; Zhu, Y.; Browning, N. D.; Pantelides, S. T.; Pennycook, S. J. Nature 2005, 435, 475-478.

(38) Momose, K.; Yonezu, H.; Fujimoto, Y.; Ojima, K.; Furukawa, Y.; Utsumi, A.; Aiki, K. Jpn. J. Appl. Phys. 2002, 41, 7301-7306.

(39) Gutjahr, J.; Sakong, S.; Kratzer, P. Nanotechnology 2014, 25, 145204.

(40) Buyanova, I.; Izadifard, M.; Kasic, A.; Arwin, H.; Chen, W.; Xin, H.; Hong, Y.; Tu, C. Phys. Rev. B 2004, 70, 085209. 
(41) Koida, T.; Chichibu, S. F.; Sota, T.; Craven, M. D.; Haskell, B. A.; Speck, J. S.; DenBaars, S. P.; Nakamura, S. Appl. Phys. Lett. 2004, 84, 3768-3770.

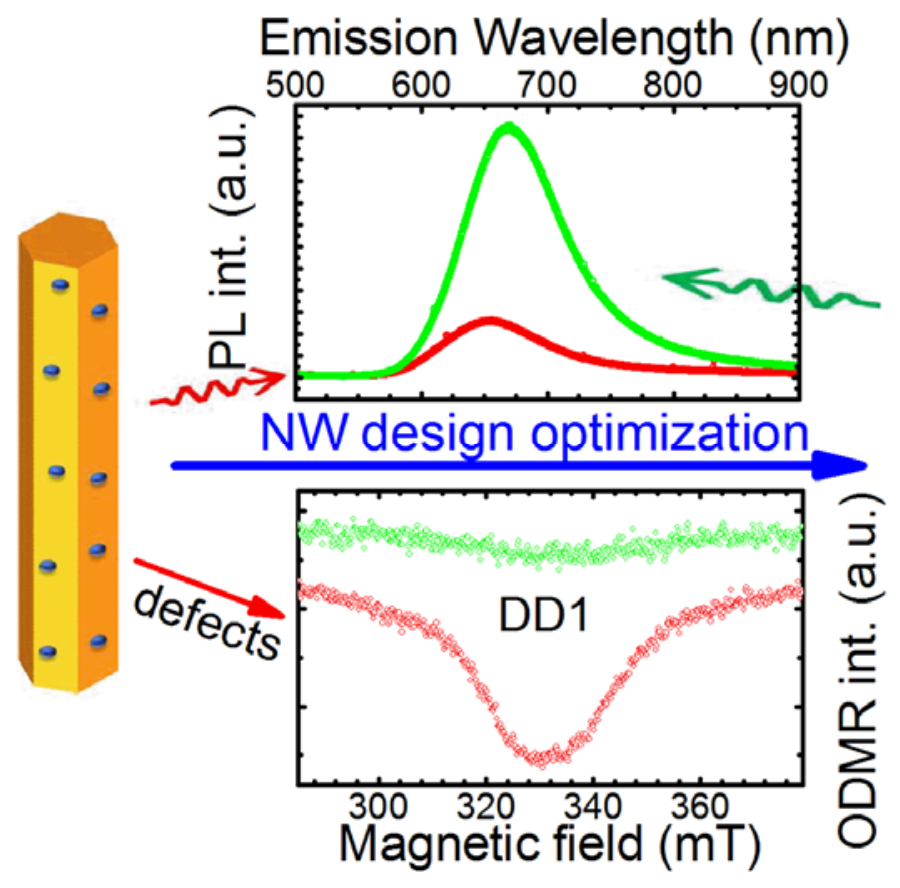

